\title{
Hydrogenative Depolymerization of Nylons
}

\author{
Amit Kumar, Niklas von Wolff, Michael Rauch, You-Quan Zou, Guy Shmul, Yehoshoa Ben-David, \\ Gregory Leitus, Liat Avram, and David Milstein*
}

Cite This: https://dx.doi.org/10.1021/jacs.0c05675

Read Online

ACCESS | W W Metrics \& More | 国 Article Recommendations | st Supporting Information

ABSTRACT: The widespread crisis of plastic pollution demands discovery of new and sustainable approaches to degrade robust plastics such as nylons. Using a green and sustainable approach based on hydrogenation, in the presence of a ruthenium pincer catalyst at $150{ }^{\circ} \mathrm{C}$ and 70 bar $\mathrm{H}_{2}$, we report here the first example of hydrogenative depolymerization of conventional, widely used nylons and polyamides, in general. Under the same catalytic conditions, we also demonstrate the hydrogenation of a polyurethane to produce diol, diamine, and methanol. Additionally, we demonstrate an example where monomers (and oligomers) obtained from the hydrogenation process can be dehydrogenated back to a poly(oligo)amide of approximately similar molecular weight, thus completing a closed loop cycle for recycling of polyamides. Based on the experimental and density functional theory studies, we propose a catalytic cycle for the process that is facilitated by metal-ligand cooperativity. Overall, this unprecedented trans-

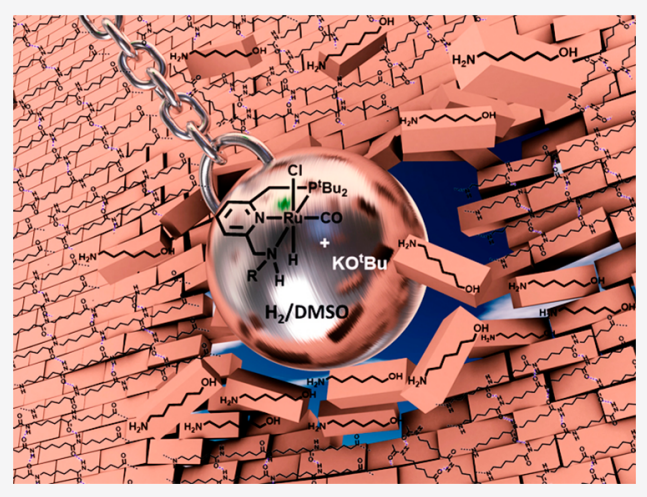
formation, albeit at the proof of concept level, offers a new approach toward a cleaner route to recycling nylons.

\section{INTRODUCTION}

Nylons are commonly used plastics with a current global market of more than 8 million tons per annum, which is expected to grow at the rate of $2.2 \%$, reaching up to 10.4 million tons, equivalent to 47.0 billion USD by $2027 .{ }^{1}$ Inevitably, the ubiquity of nylons and their nonbiodegradable nature have resulted in increased land and ocean pollution, posing a severe threat to our ecosystem. ${ }^{2}$ Therefore, it is critical that efficient and sustainable technologies for the recycling of plastics such as nylons are developed. The current plastic recycling technologies are mostly based on mechanical recycling-converting one form of plastic to another by mechanical reprocessing (melting and re-extrusion): for example, converting plastic bottles to fibers. However, mechanical recycling produces poor quality of plastic, and the number of times a plastic can be mechanically recycled is also limited. ${ }^{3}$ Distinct from mechanical recycling, chemical recycling involves depolymerization of a plastic to produce the monomer raw material from which the same virgin plastic can be made. ${ }^{3}$ Thus, only chemical recycling closes the loop of plastic production and is a sustainable mode of recycling. The reported chemical recycling methods for nylons are mainly based on pyrolysis, hydrolysis, or aminolysis-all of which require harsh reaction conditions (such as temperatures $\left.\geq 250-300{ }^{\circ} \mathrm{C}\right){ }^{4}$ Other methods based on glycolysis or aminoglycolysis do not result in the efficient regeneration of nylons from the degraded polymers. ${ }^{5}$ Thus, development of new, efficient, and sustainable methods to depolymerize nylons for the purpose of recycling is highly desirable.
Catalytic hydrogenation is an atom-economic, green, and sustainable route for organic transformations as (a) it does not produce stoichiometric waste as in the case of conventional reducing agents and (b) hydrogen gas can potentially be produced from renewable sources. ${ }^{6}$ In the past, we reported an efficient ruthenium pincer catalyst $\left(\mathbf{1}^{\prime}\right)$ for the hydrogenation of amides via $\mathrm{C}-\mathrm{N}$ bond cleavage to form alcohols and amines (Figure 1Ai). ${ }^{7}$ Several other homogeneous catalysts based on ruthenium, ${ }^{8-17}$ iron, ${ }^{18-21}$ and manganese ${ }^{22}$ have also been reported for the hydrogenation of amides to form alcohols and amines. $^{23,24}$ Additionally, we also reported acceptorless dehydrogenative coupling of alcohols and amines to form amides catalyzed by ruthenium pincer complex 2' (Figure 1Aii). ${ }^{25}$ In this direction, Guan ${ }^{26}$ and $\mathrm{we}^{27}$ independently reported the synthesis of polyamides via dehydrogenative coupling of diols and diamines using the ruthenium pincer catalyst $2^{\prime}$ (Figure 1Aiii). In order to develop a closed loop cycle, we envisioned that it might be possible to achieve the very challenging catalytic hydrogenative depolymerization of polyamides to their monomers such as diols and diamines or amino alcohols (Figure 1Aiv). Saito and co-workers have briefly mentioned an example of Ru-catalyzed hydrogenation

Received: May 25, 2020

Published: July 24, 2020 


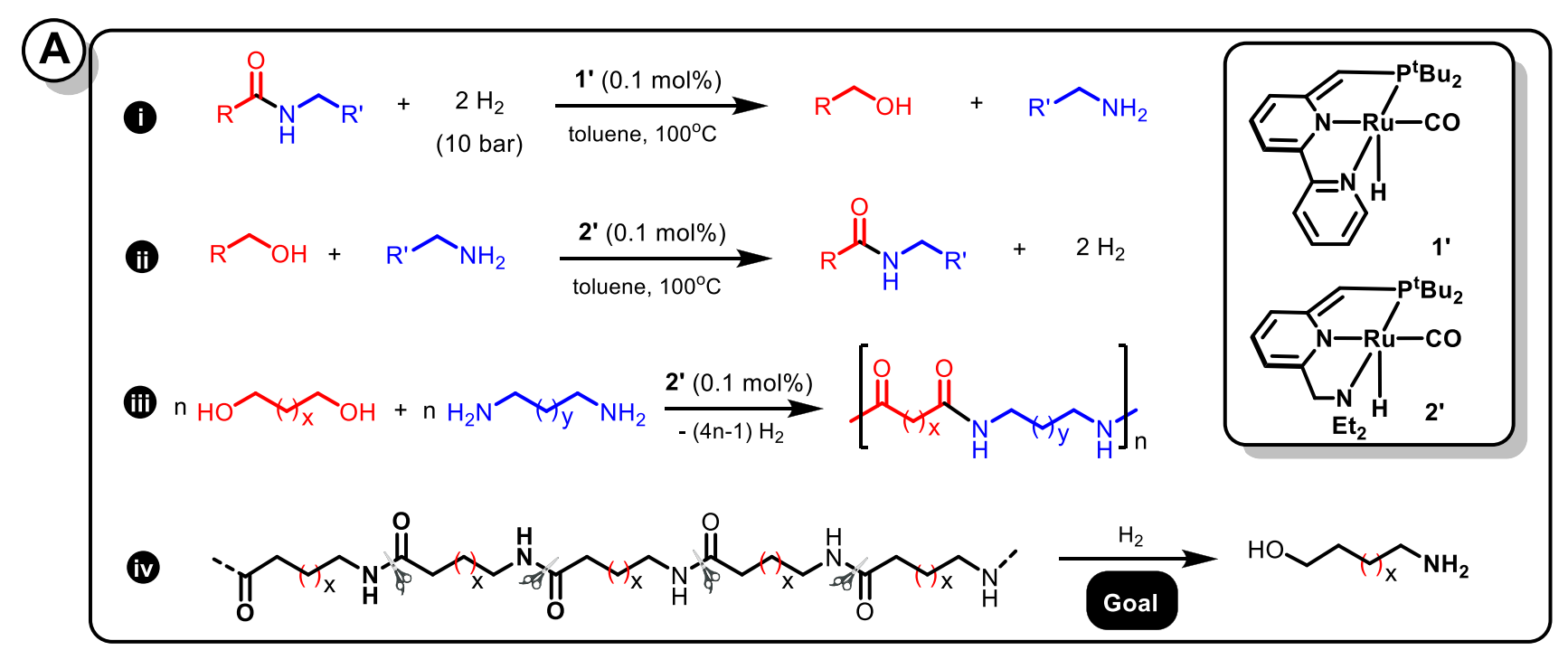

(B)

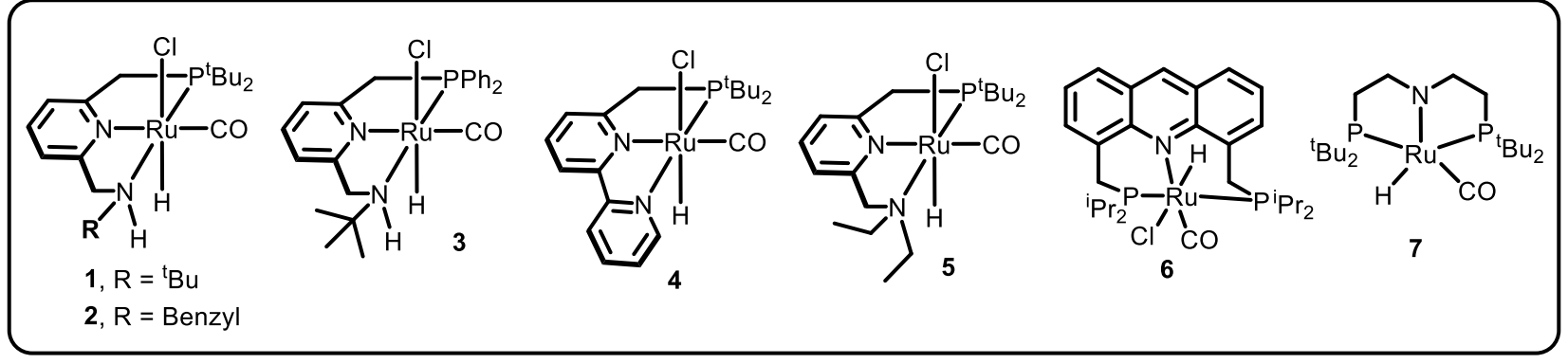

Figure 1. (A) (i) Hydrogenation of amides via $\mathrm{C}-\mathrm{N}$ bond cleavage to form alcohols and amines; (ii) dehydrogenative coupling of alcohols and amines to form amides; (iii) dehydrogenative coupling of diols and diamines to form polyamides; (iv) hydrogenation of polyamides via $\mathrm{C}-\mathrm{N}$ bond cleavage to form monomers. (B) Ruthenium complexes used in this study.

of specialized, water-soluble functionalized polyamides, although the structures of the polyamides and the hydrogenation products thereof were not reported. ${ }^{15}$ Hydrogenative depolymerization of polyesters and polycarbonates was also reported previously. ${ }^{28}$ However, we are not aware of any report on the catalytic hydrogenation of conventional nylons such as nylon-6, nylon-66, or nylon-12 or related polyamides, in general, which are highly robust and resistant to solvents. We report here our findings on the depolymerization of nylons using a ruthenium-catalyzed hydrogenation process.

\section{RESULTS AND DISCUSSION}

A major challenge in the chemical reactivity of nylons is their resistance to solvents and reagents due to the multiple, strong intermolecular hydrogen bonding interactions between the polymer chains. We started our investigation by searching for a solvent that would (a) be capable of dissolving nylon-6 and (b) be compatible with $\mathrm{Ru}$ pincer complex-catalyzed hydrogenation. We previously reported that complex 1 (Figure $1 B$ ) in the presence of 2 (or more) equiv (relative to 1 ) of base is a highly active catalyst for the hydrogenation of esters and amides. ${ }^{29,30}$ Under the catalytic conditions using 1 ( $\left.2 \mathrm{~mol} \%\right)$, $\mathrm{KO}^{t} \mathrm{Bu}(8 \mathrm{~mol} \%)$, and $\mathrm{H}_{2}(60 \mathrm{bar})$ for $48 \mathrm{~h}$ at $135{ }^{\circ} \mathrm{C}$, we screened several solvents $(2.5 \mathrm{~mL})$ for the catalytic hydrogenation of nylon-6 $(1 \mathrm{mmol}$, commercial resins with a size of 2-3 mm, $\left.M_{\mathrm{w}}=\sim 10,000\right)$. As ruthenium PNN complexes react with acids, resulting in their deactivation as catalysts, ${ }^{31}$ we avoided using acids such as formic acid or acetic acid as solvents even though they are known to dissolve nylons. No conversion of nylon- 6 was observed when toluene, tetrahydrofuran (THF), 1,4-dioxane, water, or dimethylformamide was used under the catalytic conditions described above, and resins of nylon-6 were completely recovered unreacted, presumably due to the insolubility of nylon- 6 in these solvents (Table S1; see the Supporting Information). We then employed dimethylsulfoxide (DMSO) as a solvent as it can dissolve nylon- 6 at increased temperature $(40 \mathrm{~g} / 100 \mathrm{~mL}$ at $\left.130{ }^{\circ} \mathrm{C}\right) .{ }^{32}$ In addition to the ability of solubilizing nylons, DMSO has also been claimed as an environmentally friendly solvent as it can be prepared from renewable sources, exhibits toxicity lower than that of several other polar solvents, and is biodegradable. ${ }^{33}$ Because of such unique properties, coupled with low cost, DMSO has been utilized in several industrial processes as a solvent or reagent. ${ }^{33}$ Encouragingly, in the case of DMSO solvent, a mixture of a solution and a white precipitate was obtained at the end of the hydrogenation, suggestive of a partial solubilization or degradation of nylon- 6 . Indeed, analysis of the reaction mixture by gas chromatography (GC) revealed the formation of 6-amino-1-hexanol in 14\% yield. Additionally, some other signals suggestive of oligomers were observed by GC. High-resolution electrospray ionization mass spectrometry (HR-ESI-MS) and matrix-assisted laser desorption/ionization time-of-flight (MALDI-TOF) spectrometry as well as NMR spectroscopy confirmed the presence of 6amino-1-hexanol and oligoamides (dimer-tetramer). Additionally, diffusion-ordered spectroscopy (DOSY) showed that the average size of the formed oligoamides is approximately 3 times that of 6-amino-1-hexanol. The conversion of nylon was 
Table 1. Catalyst Screening for the Hydrogenative Depolymerization of Resins of Nylon- $6^{a}$

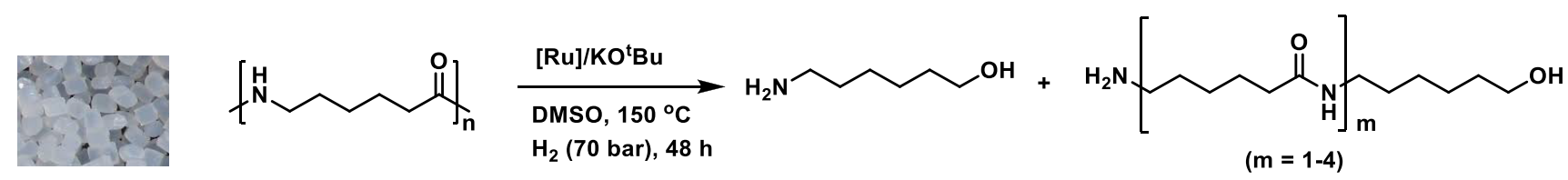

\begin{tabular}{|c|c|c|c|c|c|c|}
\hline entry & $\begin{array}{l}\text { complex } \\
(2 \mathrm{~mol} \%)\end{array}$ & $\mathrm{KO}^{t} \mathrm{Bu}$ & conversion & $\begin{array}{c}\text { amino alcohol selectivity } \\
\text { (yield \%) }\end{array}$ & $\begin{array}{c}\text { oligoamide detection (monomer/dimer/ } \\
\text { trimer) }\end{array}$ & remark \\
\hline 1 & 1 & $8 \mathrm{~mol} \%$ & $77 \%$ & $24 \%$ & yes $(3: 4: 2)$ & no resins recovered \\
\hline 2 & 2 & $8 \mathrm{~mol} \mathrm{\%}$ & $80 \%$ & $26 \%$ & yes $(3: 4: 2)$ & no resins recovered \\
\hline 3 & 3 & $8 \mathrm{~mol} \mathrm{\%}$ & $66 \%$ & $16 \%$ & yes $(3: 6: 4)$ & no resins recovered \\
\hline 4 & 4 & $2 \mathrm{~mol} \%$ & $30 \%$ & not detected & yes & resins recovered (broken) \\
\hline 5 & 5 & $2 \mathrm{~mol} \%$ & $22 \%$ & not detected & yes & resins recovered (broken) \\
\hline 6 & 6 & $2 \mathrm{~mol} \%$ & $0 \%$ & not detected & no & resins recovered \\
\hline 7 & 7 & $0 \mathrm{~mol} \%$ & $0 \%$ & not detected & no & resins recovered \\
\hline 8 & $1^{\prime}$ & $0 \mathrm{~mol} \%$ & $22 \%$ & not detected & yes & resins recovered (broken) \\
\hline 9 & $2^{\prime}$ & $0 \mathrm{~mol} \%$ & $18 \%$ & not detected & yes & resins recovered (broken) \\
\hline
\end{tabular}

${ }^{a}$ Catalytic conditions: nylon-6 $\left(117 \mathrm{mg}, 1 \mathrm{mmol}\right.$ relative to the mol wt of the monomer), complex $(0.02 \mathrm{mmol}), \mathrm{KO}{ }^{t} \mathrm{Bu}(2-9 \mathrm{mg}, 0.02-0.08$ $\mathrm{mmol})$ as specified, DMSO $(2.5 \mathrm{~mL})$, temperature $150{ }^{\circ} \mathrm{C}$, reaction time $48 \mathrm{~h}$, and $\mathrm{H}_{2}(70 \mathrm{bar})$. Conversion is based on the weight of soluble materials after hydrogenation (see the Supporting Information). Monomer means amino alcohol. The ratio of monomer/dimer/trimer has been estimated by the LC-MS. "Resins recovered" means complete recovery of resins with the shape and size intact. "Resins recovered (broken)" means that the resins were broken into small pieces after the reaction.

determined by measuring the weights of the solid reaction mixture before and after the reaction, as nylon- 6 has no solubility in DMSO at room temperature (see the Supporting Information for details). Based on this method, the conversion of nylon- 6 was determined to be $65 \%$. Additional solvents such as anisole, hexamethylphosphoramide, 1-butyl-3-methyl imidazolium octyl sulfate, diglyme, and meta-cresol were also screened under the same catalytic conditions (Table S1; see the Supporting Information), but we did not obtain any better results than when using DMSO.

Further, we optimized the catalytic conditions by varying base loading, temperature, pressure, reaction time, ruthenium complexes (see Table 1), and additives such as water, molecular sieves, and Lewis acids (see the Supporting Information for the table of optimization). Best results were obtained using 1 or $2(2 \mathrm{~mol} \%), \mathrm{KO}^{t} \mathrm{Bu}(8 \mathrm{~mol} \%), 70$ bar of $\mathrm{H}_{2}$, and $150{ }^{\circ} \mathrm{C}$ (oil bath temperature) for $48 \mathrm{~h}$, which resulted in 77-80\% conversion of nylon-6 (resins) and formation of 6amino-1-hexanol in $24-26 \%$ yield (Table 1, entries $1-2$ and Table 2, entry 1 ), with the remaining being oligomers (dimertetramer). As complexes $\mathbf{1}$ and $\mathbf{2}$ exhibited comparable catalytic activity (Table 1), we used complex 1 for further studies as it is relatively easier to synthesize compared to complex 2.

One of the reasons for the lower yield of 6-amino-1-hexanol could be catalyst deactivation over time. Hence, in order to achieve better yields of 6-amino-1-hexanol, we attempted sequential hydrogenation of nylon-6. After the first hydrogenation in DMSO under the optimized catalytic conditions, 2 mol \% of complex 1 and $8 \mathrm{~mol} \%$ of $\mathrm{KO}^{t} \mathrm{Bu}$ were added back to the mixture, and the autoclave was pressurized with 70 bar of $\mathrm{H}_{2}$ and heated at $150{ }^{\circ} \mathrm{C}$ for another $72 \mathrm{~h}$. Following both hydrogenation steps, $99 \%$ of nylon-6 was depolymerized to form 6-amino-1-hexanol (37\%) and a mixture of oligoamides (Table 2, entry $1^{\mathrm{b}}$; see the Supporting Information, section 9). We found that if not for a matter of solubility, then THF or 1,4-dioxane is a better solvent than DMSO for hydrogenation of amides using complex 1 (see the Supporting Information, section 14.4). Thus, we developed an additional approach in which, after the first step of hydrogenation, we distilled off the DMSO and added 1,4-dioxane along with complex 1 (2 mol $\%), \mathrm{KO}^{t} \mathrm{Bu}(8 \mathrm{~mol} \%)$, and $\mathrm{H}_{2}$ (70 bar), and the autoclave was heated at $150{ }^{\circ} \mathrm{C}$ for an additional $72 \mathrm{~h}$. Interestingly, this resulted in a higher yield of 6-amino-1-hexanol (48\%), although a lower conversion of nylon-6 (80\%) was observed compared to the aforementioned process when DMSO was used for both the steps, presumably due to a lower solubility of nylon-6 in dioxane (Table 2 , entry $1^{c}$; see the Supporting Information, section 9).

In order to explore the generality of this depolymerization reaction, we attempted the hydrogenation of other nylons. A powder form of commercial nylon-6 $\left(M_{\mathrm{w}} \sim 11,000\right)$ was also depolymerized ( $85 \%$ conversion) under the optimized catalytic conditions $\left(2 \mathrm{~mol} \%\right.$ of $1,8 \mathrm{~mol} \%$ of $\mathrm{KO}^{t} \mathrm{Bu}, 70$ bar of $\mathrm{H}_{2}$ at $150{ }^{\circ} \mathrm{C}$ ) to produce 6-amino-1-hexanol in $32 \%$ yield, with the remainder being oligomers as observed for the hydrogenation of nylon-6 resins (Table 1, entry 2, top row). Under the same catalytic conditions, but using complex 2 , a slightly better yield of 6-amino-1-hexanol (36\%) was observed. Interestingly, when a catalytic combination of $2(5 \mathrm{~mol} \%)$ and $\mathrm{KO}^{t} \mathrm{Bu}(20 \mathrm{~mol} \%)$ was used for $72 \mathrm{~h}$, maintaining the remaining conditions, $99 \%$ conversion of nylon-6 was observed and 6-amino-1-hexanol was detected in $55 \%$ yield based on GC analysis, with the rest being the oligomers (Table 2 , entry $2^{\mathrm{d}}$ ). The products were also confirmed by HR-ESI-MS and NMR spectroscopy. Liquid chromatography (LC)-ESI-MS was used to estimate the amount of formed oligomers, showing a ratio of monomer, dimer, and trimer of 3:4:2 (see the Supporting Information for yields of the formed oligomers estimated by the LC-ESI-MS).

Given the satisfactory result of the hydrogenative depolymerization of nylon-6, we explored the hydrogenation of other polyamides. Commercial resins of nylon-12 (purchased from Sigma-Aldrich) were also hydrogenated using the optimized catalytic condition to obtain a mixture of 12-aminododecan-1-ol and smaller oligomers (dimer and trimer, Table 2, entry 3). Additionally, we also prepared some polyamides using the dehydrogenative coupling route reported previously by us ${ }^{27}$ and then attempted to depolymerize them. 
Table 2. Substrate Scope for the Catalytic Hydrogenative Depolymerization of Polyamides ${ }^{a}$

Entry Polymer

\section{Form Mol Wt}

Conversion
Selectivity (yield of amino alcohols, diols/diamines)
1.<smiles>CC(C)CC(=O)CCCCCNC(C)C</smiles>

2.<smiles>CC(C)CC(=O)CCCCCNC(C)C</smiles>

3.<smiles>CC(C)NCCCCCCCCCCCC(=O)c1ccccc1</smiles>

4.<smiles>CC(C)(C)NCCCCCCNC(=O)CCCCC(=O)C(C)(C)C</smiles>

5.<smiles>CCOC(=O)c1ccc(C(=O)NCc2ccc(CNC(C)C)cc2)cc1</smiles>

6.<smiles>CCCCCCCCCNCCCCCCNC(=O)c1ccc(C(=O)C(C)C)cc1</smiles>

7.<smiles>CCC(C)C(=O)CCCCC(=O)NCc1ccc(CNC(C)C)cc1</smiles>

8.<smiles>CNCc1ccc(CNC(=O)C(=O)C(C)C)cc1</smiles>

9.<smiles>CC(C)NC1CCC(CC2CCC(NC(=O)OCCCCOC(C)NC3CCCCC3C)CC2)CC1</smiles>

resins

10,000

$77 \%$

$99 \%^{\mathrm{b}}$

$80 \%{ }^{c}$

powder

11,000

$85 \%$

$99 \%^{d}$

$32 \%$

$55 \%{ }^{d}$

resins $^{e}$

$-$

$80 \%$

$30 \%$

powder

3500

$60 \%$

$20 \%$ (diol) $25 \%$ (diamine)

powder

1500

$99 \%$

$80 \%$ (diol) $85 \%$ (diamine)

powder

4500

$80 \%$

$42 \%$ (diol)

$45 \%$ (diamine)

$75 \%$ (diol)

powder

2500

$95 \%$

$74 \%$ (diamine) $\operatorname{resins}^{\mathrm{e}}$

powder

1500

$95 \%$

$77 \%$ (diol)

$82 \%$ (diamine)

$70 \%$ (diol)

$90 \%$

${ }^{a}$ Catalytic conditions: polyamide $\left(1 \mathrm{mmol}\right.$ relative to the molecular weight of the monomer), complex $1(0.02 \mathrm{mmol}), \mathrm{KO}{ }^{t} \mathrm{Bu}(0.08 \mathrm{mmol})$, DMSO $(2.5 \mathrm{~mL}), \mathrm{H}_{2}(70 \mathrm{bar})$, temperature $150{ }^{\circ} \mathrm{C}$, and reaction time $48 \mathrm{~h} .{ }^{b}$ Two sequential hydrogenation steps both in DMSO (vide supra). ${ }^{c^{c}}$ Two sequential hydrogenation steps first in DMSO and second in 1,4-dioxane (vide supra). ${ }^{d_{2}}(0.05 \mathrm{mmol})$ and $\mathrm{KO}^{t} \mathrm{Bu}(0.2 \mathrm{mmol}), 72 \mathrm{~h}$, remaining conditions as above in footnote a. ${ }^{e}$ Molecular weight could not be determined.

Under the optimized catalytic conditions, $60 \%$ conversion of nylon-66 was observed and 1,6-hexane diol and hexamethylene diamine were detected in 20 and $25 \%$ yields, respectively (entry 4). A low molecular weight polyamide prepared by the dehydrogenative coupling of 1,4-phenylenedimethanol and 1,4-phenylenedimethanamine was hydrogenated to afford $80 \%$ diol and $85 \%$ diamine (entry 5). Some other synthesized poly(oligo)amides with the combination of aliphatic and aromatic parts were also successfully hydrogenated to produce diols and diamines (entries 6-8). Further, we extended this concept to the hydrogenation of polyurethanes, which are also commonly used plastics and can be prepared from $\mathrm{CO}_{2}{ }^{34}$ Thus, hydrogenation of polyurethanes (to diols, diamines, and methanol) is beneficial not only for the recycling purpose but also for the indirect conversion of $\mathrm{CO}_{2}$ to methanol. Under the same catalytic conditions (Table 2, entry 9), using complex 1 $(2 \mathrm{~mol} \%)$ and $\mathrm{KO}^{t} \mathrm{Bu}(8 \mathrm{~mol} \%)$, commercial resins of a polyurethane were hydrogenated to afford 1,4-butanediol (70\%), 4,4'-methylenebis(cyclohexan-1-amine) (66\%), and methanol $(45 \%)$. With the recent growth in the notion of 
circular chemistry (economy), ${ }^{35}$ we also demonstrated as a proof of concept that the catalytic hydrogenation/dehydrogenation process can be utilized for the development of a closed loop cycle for polyamide synthesis/degradation. The monomers and oligomers obtained (after removal of DMSO) from the reaction mixture described in Table 2, entry 5, were refluxed in 1,4-dioxane solvent containing complex 5 ( $1 \mathrm{~mol}$ $\%)$ and $\mathrm{KO}^{t} \mathrm{Bu}(1 \mathrm{~mol} \%)$ for $48 \mathrm{~h}$ to produce the corresponding polyamide of $1600 \mathrm{~mol} \mathrm{wt}$, similar to that used for hydrogenation (entry 5; also see the Supporting Information, section 13).

Intrigued by the catalytic activity of the ruthenium pincer complexes $\mathbf{1}$ and $\mathbf{2}$ for the hydrogenation of polyamides, we explored the mechanism of the hydrogenative depolymerization process. The excellent ability of DMSO to disrupt the hydrogen bonding in amides and peptides was reported previously using NMR spectroscopy and density functional theory (DFT) studies. ${ }^{36,37}$ We found that using complex 1 (2 mol \%) and $\mathrm{KO}^{t} \mathrm{Bu}(8 \mathrm{~mol} \%)$, only a trace amount of DMSO is hydrogenated under 70 bar of $\mathrm{H}_{2}$ in THF $\left(150{ }^{\circ} \mathrm{C}, 24 \mathrm{~h}\right)$. We detected $\mathrm{Me}_{2} \mathrm{~S}$ only in a trace quantity under the reaction conditions of hydrogenation of nylons using DMSO as solvent. These experiments indicate that complex $\mathbf{1}$ is not a good catalyst for the hydrogenation of DMSO, availing the catalyst for the hydrogenation of polyamides in DMSO as solvent. Additionally, reaction of complex 1 with 4 equiv of $\mathrm{KO}^{t} \mathrm{Bu}$ in DMSO- $d_{6}$ shows formation of a doubly deprotonated anionic complex $\mathbf{A}$ in THF reported by us previously. ${ }^{30}$ The ${ }^{1} \mathrm{H}$ NMR spectrum in DMSO- $d_{6}$ exhibited a hydride signal $[\delta-18.19$ (d, $\left.\left.{ }^{2} J_{\mathrm{H}, \mathrm{P}}=27.0 \mathrm{~Hz}, 1 \mathrm{H}\right)\right]$ very close to that observed in THF- $d_{8}[\delta$ $\left.-18.45\left(\mathrm{~d},{ }^{2} J_{\mathrm{H}, \mathrm{P}}=28.0 \mathrm{~Hz}, 1 \mathrm{H}\right)\right]$ where the hydride is located trans to a vacant coordination site (Scheme 1i). ${ }^{30}$ This indicates that DMSO is likely not coordinated to the ruthenium center, making the vacant coordinate site available for the hydrogenation reaction.

In order to gain further mechanistic insight, we studied the reaction of nylon-6 (powder form, $M_{\mathrm{w}}=11,000$ ) with the in situ prepared complex A in DMSO- $d_{6}$ using variable-temperature NMR spectroscopy (Scheme 1ii). No reaction was observed when the temperature was gradually increased from

Scheme 1. (i) Reaction of Complex 1 with $\mathrm{KO}^{t} \mathrm{Bu}$ and $\mathrm{H}_{2}$, Formation of Complexes A and C, (ii) Reaction of Complex A with Nylon-6 and $\mathrm{H}_{2}$, and (iii) Reaction of Complex 1/ $\mathrm{KO}^{t} \mathrm{Bu}$ with the Diamide $N^{1}, N^{2}$-Bis $(4-$ methoxybenzyl)oxalamide

(i)

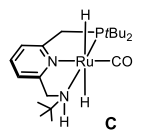

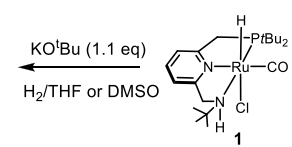
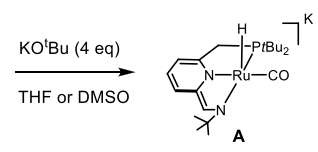

(ii)

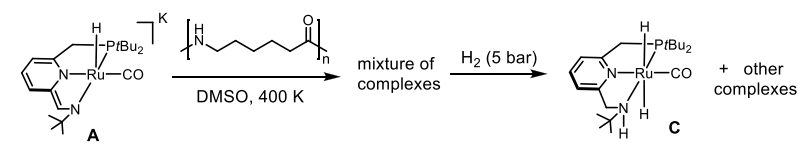

(iii)
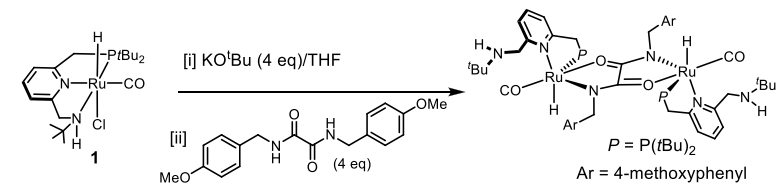

B
298 to $360 \mathrm{~K}$, but interestingly, at $400 \mathrm{~K}$, the hydride signal in the ${ }^{1} \mathrm{H}$ NMR spectrum completely disappeared and the corresponding ${ }^{31} \mathrm{P}\left\{{ }^{1} \mathrm{H}\right\}$ NMR spectrum showed a mixture of species. This might indicate insertion of one of the carbonyl groups of nylon- 6 into the $\mathrm{Ru}-\mathrm{H}$ bond. Addition of $\mathrm{H}_{2}$ ( 5 bar) to the same NMR tube at $298 \mathrm{~K}$ resulted in the formation of multiple ruthenium hydride species in the ${ }^{1} \mathrm{H}$ NMR spectrum featured by broad signals at $\delta-5.56,-5.78,-10.30$, and -11.34 . The signals at $\delta-5.56$ and -5.78 agree well with the ruthenium trans dihydride complex $\mathbf{C}$ that was independently prepared by the reaction of complex 1 with $\mathrm{KO}^{t} \mathrm{Bu}$ and $\mathrm{H}_{2}$ (Scheme 1i, with hydride signals at $\delta-4.73\left(\mathrm{~d},{ }^{2} J_{\mathrm{H}, \mathrm{P}}=14.9\right.$ $\mathrm{Hz})$ and $-5.12\left(\mathrm{~d},{ }^{2} J_{\mathrm{H}, \mathrm{P}}=17.6 \mathrm{~Hz}\right)$ in THF- $d_{8}$ and at $\delta-5.23$ $\left(\mathrm{d},{ }^{2} J_{\mathrm{H}, \mathrm{P}}=15.7 \mathrm{~Hz}\right)$ and $-5.42\left(\mathrm{~d},{ }^{2} J_{\mathrm{H}, \mathrm{P}}=16.0 \mathrm{~Hz}\right)$ in DMSO$\left.d_{6}\right)$. The ${ }^{31} \mathrm{P}\left\{{ }^{1} \mathrm{H}\right\}$ NMR spectrum of the reaction mixture after addition of $\mathrm{H}_{2}$ also showed a mixture of complexes, including a signal at $\delta 123.9$, very close to that of complex $\mathbf{C}(\delta 123.5$ in THF- $d_{8}, \delta 122.93$ in DMSO- $d_{6}$ ).

A similar observation was made upon reaction of complex $\mathbf{A}$ with $N$-benzyl benzamide (see the Supporting Information, section 14.4). We also studied the reactivity of complex $\mathbf{A}$ with a diamide (Scheme 1iii). Reaction of an in situ prepared complex $\mathbf{A}$ in THF or toluene- $d_{8}$ with $N^{1}, N^{2}$-bis $(4-$ methoxybenzyl)oxalamide (4 equiv) resulted in the formation of a mixture of complexes (see the Supporting Information, section 14.5). Interestingly, a single crystal obtained from this reaction mixture revealed a diruthenium complex $\mathbf{B}$ (see the Supporting Information, Figure S56), featuring $\mathrm{N}-\mathrm{H}$ activation of both amide groups. Significantly, both the $\mathrm{C}=$ $\mathrm{O}$ groups of the two amide moieties were found to coordinate to the two ruthenium centers, opening the amine side arm of the pincer ligand. Hemilability of the amine side arms in the case of PNNH pincer complexes of ruthenium and manganese was proposed a few times in catalytic (de)hydrogenation reactions. ${ }^{29,38-40}$ Notably, this is the first crystal structure providing direct evidence for the hemilability of a PNNH pincer complex relevant to catalysis. The size of complex $\mathbf{B}$ as a dimer was also confirmed in the solution by DOSY NMR spectroscopy.

To obtain further insights into the mechanism, we employed DFT calculations at the $\omega \mathrm{B} 97 \mathrm{M}-\mathrm{V} /$ def2-TZVPP/RICOSX/ $\mathrm{SMD} / / \mathrm{M} 06-\mathrm{L} / \mathrm{def} 2 \mathrm{TZVP} / \mathrm{GD} 3 /$ W06 level of theory. We suggest that the first step involves deprotonation of the precatalyst $\mathbf{1}$ at the benzylic position of the ligand P-arm to generate the dearomatized complex $\mathbf{D}$ (as observed experimentally). ${ }^{30}$ In-depth experimental thermodynamic analysis showed that, for a similar PNP-Ru complex, the dearomatized form can be in equilibrium with different Lewis or Brønsted acids to undergo reversible rearomatization. ${ }^{41}$ From a computational point of view, the amido $\mathrm{N}-\mathrm{H}$ bond of a simple test amide seems not to be acidic enough to generate higher concentrations of $\mathbf{F}(+9.1 \mathrm{kcal} / \mathrm{mol})$ nor to be a good chelate $(\mathrm{E},+9.6 \mathrm{kcal} / \mathrm{mol})$, in contrast to recent findings involving formamides. ${ }^{42}$ On the other hand, other deprotonated species such as $\mathrm{N}$-arm dearomatized $\mathbf{D}^{\prime}(+5.9 \mathrm{kcal} / \mathrm{mol})$ or $\mathrm{N}-\mathrm{H}$ deprotonated $\mathbf{D}^{\prime \prime}(-0.3 \mathrm{kcal} / \mathrm{mol})$ should be accessible under the employed reaction conditions.

Our calculations suggest that the hydrogenation reaction proceeds via two connected catalytic cycles involving the dearomatized complex $\mathbf{D}$ and the trans-dihydride complex $\mathbf{C}$ formed upon hydrogen activation of $\mathbf{D}$ (Scheme 2). Importantly, although the reaction is run at high temperature, which was shown to disfavor the $\mathrm{H}_{2}$-splitting thermodynam- 
Scheme 2. Proposed Mechanism for the Hydrogenation of Amides Using DFT Calculations

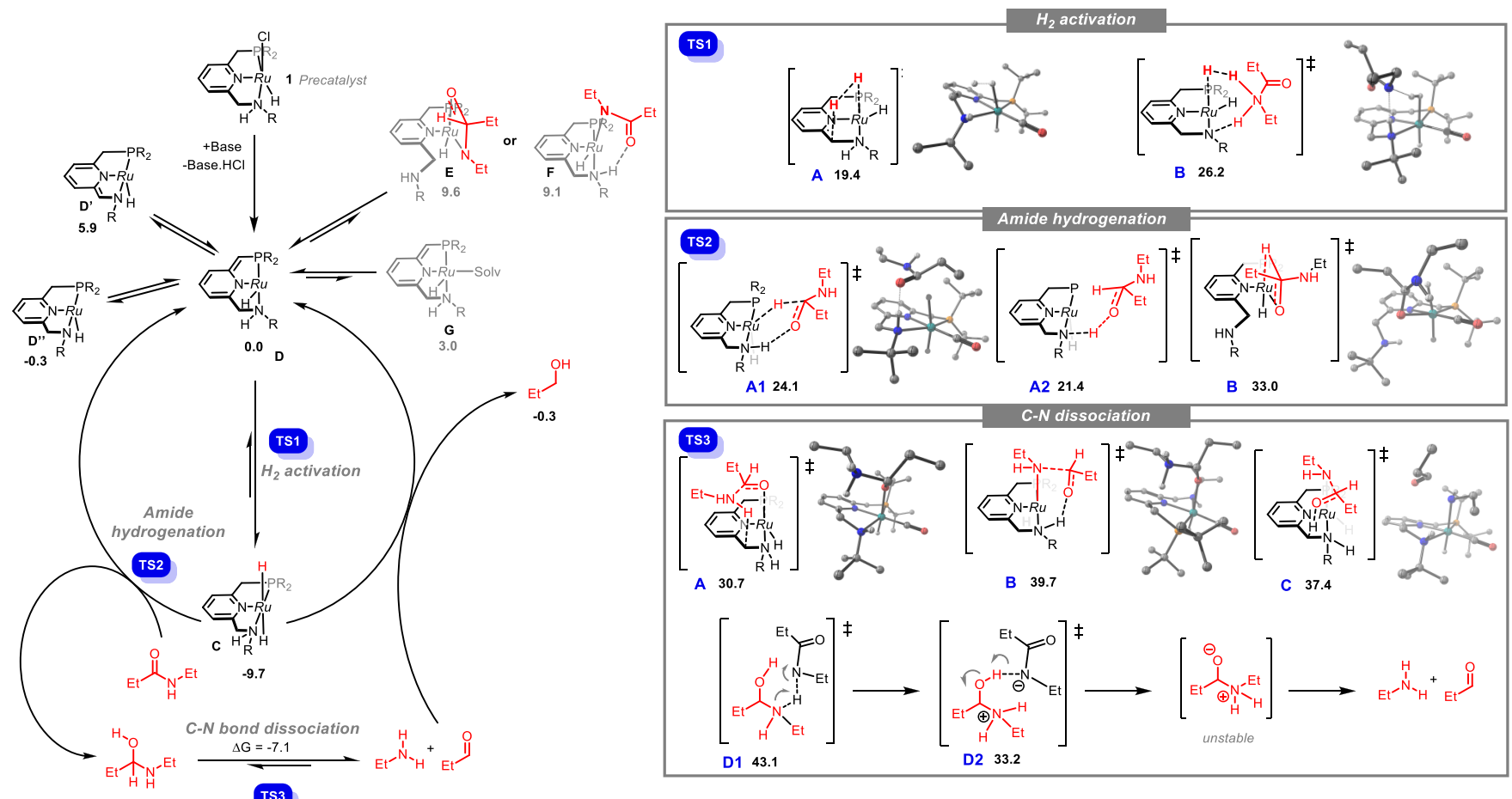

ics, $^{41}$ formation of the dihydride species $\mathbf{C}$ is energetically downhill $(-9.7 \mathrm{kcal} / \mathrm{mol})$. This emphasizes the importance of relatively high pressures to generate high concentrations of $\mathbf{C}$ in this challenging amide hydrogenation. Previously reported experimental and theoretical studies implicate an important role of proton relays and solvation for this step. ${ }^{43-45}$

As the reaction proceeds, both alcohols and amines are generated and are very likely involved in this step. Although not rate-determining and oversimplified, we wish to emphasize that we find the lowest barriers for $\mathrm{H}_{2}$ splitting from $\mathbf{D}^{\prime}$ (TS1A, $19.4 \mathrm{kcal} / \mathrm{mol}$ ), with the test amide not acidic/basic enough to facilitate this step (TS1B, $26.2 \mathrm{kcal} / \mathrm{mol}$ ). In the first catalytic cycle, the hydrogen activation step is followed by the hydrogenation of an amide bond by the trans-dihydride complex $\mathbf{C}$ to form hemiaminal and regeneration of the dearomatized complex D. Given the experimental evidence for ligand hemilability in the presence of the diamide in $\mathbf{B}$ (Scheme 1iii), we probed if this would be a viable pathway for amide hydrogenation. However, we find a stepwise Noyoritype mechanism to be more favorable with hydride transfer (TS2A1, $24.1 \mathrm{kcal} / \mathrm{mol}$ ) preceding proton transfer from the $\mathrm{N}-\mathrm{H}$ group (TS2A2, $21.4 \mathrm{kcal} / \mathrm{mol}$ ). Indeed, hydride transfer via ligand hemilability is around $9 \mathrm{kcal} / \mathrm{mol}$ higher in energy (TS2B, $33.0 \mathrm{kcal} / \mathrm{mol}$ ).

An intriguing aspect of amide hydrogenation is the fate of the intermediate hemiaminal. We calculate its dissociation to the amine and aldehyde to be strongly favorable $(\Delta G=-7.1$ $\mathrm{kcal} / \mathrm{mol}$ ). A common notion is thus that the hemiaminal dissociates easily, as also implied by a mechanistic proposal by Sanford and co-workers. ${ }^{46}$ Similarly, Prakash and co-workers could not detect any hemiaminal intermediate during $\mathrm{CO}_{2}$ hydrogenation via formamides. ${ }^{47}$ In contrast, recent work from the Bernskoetter group indicates that hemiaminal dissociation is kinetically hindered and relies on proton-relay catalysis to occur readily. ${ }^{48}$ This is in agreement with previous DFT calculations from the same group, highlighting the TOFlimiting nature of this step that is facilitated by the employed iron complex or via proton relay by a solvent/reactant molecule. ${ }^{49}$ We were thus interested how these observations translate to our system. Again, the test amide seems not to be acidic enough to serve as an efficient proton relay for the generation of the labile zwitterion (TS3D1, $43.1 \mathrm{kcal} / \mathrm{mol}$ ). Interestingly, for $\mathrm{Fe}$ and $\mathrm{Mo}$ complexes in the absence of alcohols, ${ }^{50}$ a $\mathrm{C}-\mathrm{N}$ bond cleavage might be promoted via a $\mathrm{N}$ coordinated intermediate. In our case, such a pathway can be clearly ruled out due to very high barriers (TS3B and TS3C, 39.7 and $37.4 \mathrm{kcal} / \mathrm{mol}$, respectively). On the other hand, C$\mathrm{N}$ bond cleavage via $\mathrm{O}$-coordination (TS3A, $30.7 \mathrm{kcal} / \mathrm{mol}$ ) positions the leaving amido group for protonation by the side arm $\mathrm{CH}_{2}$ group, as observed also for the reverse reaction in a PNP-Ru complex. ${ }^{42}$ Although significantly lower in energy than the other explored pathways, it would still be linked to an energetic span of around $40 \mathrm{kcal} / \mathrm{mol}$. Anionic alkoxide species are amenable to expel very weak leaving groups (e.g., hydrides in the case of alcohol dehydrogenation). ${ }^{51}$ As amines are poor leaving groups, it might be suggested that basic conditions will favor $\mathrm{C}-\mathrm{N}$ bond cleavage. This is at least in qualitative agreement with the above-reported example of Beller's anionic Mo-alkoxo complex ${ }^{50}$ that can deprotonate the hemiaminal and facilitate subsequent $\mathrm{C}-\mathrm{N}$ cleavage via $\mathrm{H}$-bonding or the example from the Bernskoetter group where the strongly basic cocatalyst TBD (1,5,7-triazabicyclo[4.4.0] dec-5-ene) generates the highest catalytic activity. ${ }^{48}$ In another Ru-catalyzed amide hydrogenation system, basic conditions were needed to promote $\mathrm{C}-\mathrm{N}$ cleavage. ${ }^{52}$ Finally, an analogy to the cleavage to the hemiaminal might be the scission of $\mathrm{C}-\mathrm{N}$ bonds in oxaziridines, which was shown to be base-catalyzed. ${ }^{53}$ In our case, excess $\mathrm{KO}^{t} \mathrm{Bu}$ is needed for reaching high turnover numbers. Moreover, as the reaction proceeds, the reaction medium will become more basic. The generated amines and 
alcohols could further provide a stabilizing H-bond network. A preliminary surface scan of the potassium salt of the hemiaminal showed that, in the absence of an H-bonding network, the $\mathrm{C}-\mathrm{N}$ cleavage is uphill in energy but without any sizable transition state (see the Supporting Information). Clearly a more profound analysis, possibly involving explicit solvation, would be needed to assess with certainty the true nature of the $\mathrm{C}-\mathrm{N}$ bond-cleaving transition state in such amide hydrogenation reactions.

Finally, the aldehyde from the decomposition of hemiaminal is hydrogenated by $\mathbf{C}$ to form alcohol and regenerates the dearomatized complex $\mathbf{D}^{\prime \prime}$ that would again be in rapid equilibrium with $\mathbf{D}$.

\section{CONCLUSION}

In conclusion, we report here the hydrogenative depolymerization of conventional nylons such as nylon-6, other polyamides, and a polyurethane. The reaction is catalyzed by ruthenium pincer complexes using DMSO as a solvent, which plays a critical role in the process by disrupting the hydrogen bonding of the polyamide and at the same time remaining uncoordinated to the metal center, thus allowing the catalysis to occur. We also demonstrate an example where the diols and diamines obtained from the hydrogenative depolymerization process are used to synthesize the original polyamide via a ruthenium-catalyzed dehydrogenative coupling process, thus closing the loop of polyamide production. DFT calculations confirm the important role of metal-ligand cooperativity where the hydrogenation of amide bonds takes place via an outer-sphere mechanism. Methods for chemical recycling of nylons have been reported previously; however, this is the first time that a process based on hydrogenation, which is a green, sustainable, and atom-economic reaction, has been used to depolymerize conventional and robust nylons such as nylon- 6 . We believe that this unprecedented transformation, although not at a practical level yet, provides a new promising direction aimed at the highly desirable depolymerization of waste nylons as well as hydrogenation of other polyamides.

\section{ASSOCIATED CONTENT}

\section{(s) Supporting Information}

The Supporting Information is available free of charge at https://pubs.acs.org/doi/10.1021/jacs.0c05675.

Experimental details of catalytic hydrogenation, mechanistic studies, NMR, GC, ESI-MS, and X-ray data, and computational details (PDF)

Crystallographic data for $\mathbf{B}$ (CIF)

\section{AUTHOR INFORMATION}

\section{Corresponding Author}

David Milstein - Department of Organic Chemistry, The Weizmann Institute of Science, Rehovot 76100, Israel; ○ orcid.org/0000-0002-2320-0262; Email: david.milstein@ weizmann.ac.il

\section{Authors}

Amit Kumar - Department of Organic Chemistry, The Weizmann Institute of Science, Rehovot 76100, Israel

Niklas von Wolff - Laboratoire d'Electrochimie Moleculaire, UMR 7591, CNRS/University of Paris, 75013 Paris, France; (1) orcid.org/0000-0001-8108-5365
Michael Rauch - Department of Organic Chemistry, The Weizmann Institute of Science, Rehovot 76100, Israel

You-Quan Zou - Department of Organic Chemistry, The Weizmann Institute of Science, Rehovot 76100, Israel

Guy Shmul - Department of Chemical Research Support, The Weizmann Institute of Science, Rehovot 76100, Israel; (1) orcid.org/0000-0001-6710-2296

Yehoshoa Ben-David - Department of Chemical Research Support, The Weizmann Institute of Science, Rehovot 76100, Israel

Gregory Leitus - Department of Chemical Research Support, The Weizmann Institute of Science, Rehovot 76100, Israel

Liat Avram - Department of Chemical Research Support, The Weizmann Institute of Science, Rehovot 76100, Israel

Complete contact information is available at:

https://pubs.acs.org/10.1021/jacs.0c05675

\section{Notes}

The authors declare no competing financial interest.

\section{ACKNOWLEDGMENTS}

This research was supported by the European Research Council (ERC AdG 692775). D.M. holds the Israel Matz Professorial Chair of Organic Chemistry. A.K. is thankful to the Planning and Budgeting Committee of Israel and Feinberg Graduate School for a (senior) postdoctoral fellowship. Y.-Q.Z. acknowledges the Sustainability and Energy Research Initiative (SAERI) foundation for a research fellowship. M.R. acknowledges the Zuckerman STEM Leadership Program for a research fellowship. Computations were performed using HPC resources from GENCI-CINES (Grant 2019 AP010811227).

\section{REFERENCES}

(1) (a) Kind, S.; Neubauer, S.; Becker, J.; Yamamoto, M.; Volkert, M.; Abendroth, G. v.; Zelder, O.; Wittmann, C. From zero to hero Production of bio-based nylon from renewable resources using engineered Corynebacterium glutamicum. Metab. Eng. 2014, 25, 113-123. (b) Nylon Market Size, Share \& Trends Analysis Report by Product (Nylon 6, Nylon 66), by Application (Automobile, Electrical \& Electronics, Engineering Plastics, Textile), by Region, and Segment Forecasts, 2020-2027. Research and Markets, https://www. researchandmarkets.com/reports/4375423/nylon-market-size-shareand-trends-analysis (accessed 2020-08-05). (c) Global Nylon Industry, https://www.reportlinker.com/p03993523/Global-Nylon-Industry. html (accessed 2020-08-05).

(2) Geyer, R.; Jambeck, J. R.; Law, K. L. Production, use, and fate of all plastics ever made. Sci. Adv. 2017, 3, No. e1700782.

(3) (a) The New Plastics Economy: Rethinking the Future of Plastics, https://www.ellenmacarthurfoundation.org/assets/downloads/ publications/NPEC-Hybrid_English_22-11-17_Digital.pdf (accessed 2020-08-05). (b) La Mantia, F. P. Mechanical Propoerties of Recycled Nylons. Macromol. Symp. 1999, 147, 167-172. (c) Ragaert, K.; Delva, L.; Van Geem, K. Mechanical and Chemical Recycling of Solid Plastic Waste. Waste Manage. 2017, 69, 24-58. (d) Singh, N.; Hui, D.; Singh, R.; Ahuja, I. P. S.; Feo, L.; Fraternali, F. Recycling of Plastic Solid Waste: A state of Art Review and Future Applications. Composites, Part B 2017, 115, 409-422. (e) Rahimi, A.; García, J. M. Chemical Recycling of Waste Plastics for New Materials Production. Nat. Rev. Chem. 2017, 1, 0046. (f) Lu, X.-B.; Liu, Y.; Zhou, H. Learning Nature: Recyclable Monomers and Polymers. Chem. - Eur. J. 2018, 24, 11255-11266. (g) Coates, G. W.; Getzler, Y.D. Y. L. Chemical recycling to monomer for an ideal, circular polymer economy. Nat. Rev. Mater. 2020, 5, 501-516. 
(4) (a) Mihut, C.; Captain, D. K.; Gadala-Maria, F.; Amiridis, M. D. Review: Recycling of nylon from carpet waste. Polym. Eng. Sci. 2001, 41, 1457-1470. (b) Dimitis, S.; Andriotis, L. A.; Koutsidis, I. A.; Louka, D. A.; Nianias, N. P.; Siafaka, P.; Tsagkalias, I.; Tsintzou, G. Recent Advances in the Chemical Recycling of Polymers (PP, PS, LDPE, HDPE, PC, Nylon, PMMA). Material Recycling: Trends and Perspectives; InTech, 2012. (c) Alberti, C.; Figueira, R.; Hofmann, M.; Koschke, S.; Enthaler, S. Chemical Recycling of End-of-Life Polyamide 6 via Ring Closing Depolymerization. Chemistry Select 2019, 4, 12638-12642 and references therein.. (d) Corbin, T. F.; Davis, E. A.; Dellinger, J. A. Reclaiming $\varepsilon$-caprolactam from nylon 6 carpet. U.S. Patent Appl. US5169870A, 1991. (e) Commercial nyloncarpet recycling to $\varepsilon$-caprolactam or virgin nylons is operated by Shaw Industries (https://www.energy.gov/eere/amo/nylon-carpetrecycling), Aquafil (https://www.aquafil.com/where-we-are/usa/acr$1 /$ ), and DOMO chemicals (https://www.domochemicals.com/en/ markets-brands/econamid).

(5) Datta, J.; Błażek, K.; Włoch, M.; Bukowski, R. A. New Approach to Chemical Recycling of Polyamide 6.6 and Synthesis of Polyurethanes with Recovered Intermediates. J. Polym. Environ. 2018, 26, 4415-4429.

(6) Rylender, P. N. Hydrogenation Methods; Academic Press, 1985.

(7) Balaraman, E.; Gnanaprakasam, B.; Shimon, L. J. W; Milstein, D. Direct Hydrogenation of Amides to Alcohols and Amines under Mild Conditions. J. Am. Chem. Soc. 2010, 132, 16756-16758.

(8) Ito, M.; Sakaguchi, A.; Kobayashi, C.; Ikariya, T. Chemoselective Hydrogenation of Imides Catalyzed by $\mathrm{Cp} * \mathrm{Ru}(\mathrm{PN})$ Complexes and Its Application to the Asymmetric Synthesis of Paroxetine. J. Am. Chem. Soc. 2007, 129, 290-291.

(9) Ito, M.; Kobayashi, C.; Himizu, A.; Ikariya, T. Highly Enantioselective Hydrogenative Desymmetrization of Bicyclic Imides Leading to Multiply Functionalized Chiral Cyclic Compounds. J. Am. Chem. Soc. 2010, 132, 11414-11415.

(10) Ito, M.; Ootsuka, T.; Watari, R.; Shiibashi, A.; Himizu, A.; Ikariya, T. Catalytic Hydrogenation of Carboxamides and Esters by Well-Defined $\mathrm{Cp}^{*} \mathrm{Ru}$ Complexes Bearing a Protic Amine Ligand. J. Am. Chem. Soc. 2011, 133, 4240-4242.

(11) Takebayashi, S.; John, J. M.; Bergens, S. H. Desymmetrization of meso-Cyclic Imides via Enantioselective Monohydrogenation. J. Am. Chem. Soc. 2010, 132, 12832-12834.

(12) John, J. M.; Bergens, S. H. A Highly Active Catalyst for the Hydrogenation of Amides to Alcohols and Amines. Angew. Chem., Int. Ed. 2011, 50, 10377-10380.

(13) John, J. M.; Loorthuraja, R.; Antoniuk, E.; Bergens, S. H. Catalytic hydrogenation of functionalized amides under basic and neutral conditions. Catal. Sci. Technol. 2015, 5, 1181-1186.

(14) Cabrero-Antonino, J. R.; Alberico, E.; Drexler, H.-J.; Baumann, W.; Junge, K.; Junge, H.; Beller, M. Efficient Base-Free Hydrogenation of Amides to Alcohols and Amines Catalyzed by WellDefined Pincer Imidazolyl-Ruthenium Complexes. ACS Catal. 2016, $6,47-54$.

(15) Miura, T.; Naruto, M.; Toda, K.; Shimomura, T.; Saito, S. Multifaceted catalytic hydrogenation of amides via diverse activation of a sterically confined bipyridine-ruthenium framework. Sci. Rep. 2017, 7, 1586

(16) Shi, L.; Tan, X.; Long, J.; Xiong, X.; Yang, S.; Xue, P.; Lv, H.; Zhang, X. Direct Catalytic Hydrogenation of Simple Amides: A Highly Efficient Approach from Amides to Amines and Alcohols. Chem. - Eur. J. 2017, 23, 546-548.

(17) Kita, Y.; Higuchi, T.; Mashima, K. Hydrogenation of amides catalyzed by a combined catalytic system of a $\mathrm{Ru}$ complex with a zinc salt. Chem. Commun. 2014, 50, 11211-11213.

(18) Jayarathne, U.; Zhang, Y.; Hazari, N.; Bernskoetter, W. H. Selective Iron-Catalyzed Deaminative Hydrogenation of Amides. Organometallics 2017, 36, 409-416.

(19) Schneck, F.; Assmann, M.; Balmer, M.; Harms, K.; Langer, R. Selective Hydrogenation of Amides to Amines and Alcohols Catalyzed by Improved Iron Pincer Complexes. Organometallics 2016, 35, 1931-1943.
(20) Rezayee, N. M.; Samblanet, D. C.; Sanford, M. S. IronCatalyzed Hydrogenation of Amides to Alcohols and Amines. ACS Catal. 2016, 6, 6377-6383.

(21) Garg, J. A.; Chakraborty, S.; Ben-David, Y.; Milstein, D. Unprecedented iron-catalyzed selective hydrogenation of activated amides to amines and alcohols. Chem. Commun. 2016, 52, 52855288.

(22) Papa, V.; Cabrero-Antonino, J. R.; Alberico, E.; Spanneberg, A.; Junge, K.; Junge, H.; Beller, M. Efficient and selective hydrogenation of amides to alcohols and amines using a well-defined manganesePNN pincer complex. Chem. Sci. 2017, 8, 3576-3585.

(23) Smith, A. M.; Whyman, R. Review of Methods for the Catalytic Hydrogenation of Carboxamides. Chem. Rev. 2014, 114, 5477-5510.

(24) Chardon, A.; Morisset, E.; Rouden, J.; Blanchet, J. Recent Advances in Amide Reductions. Synthesis 2018, 50, 984-997.

(25) Gunanathan, C.; Ben-David, Y.; Milstein, D. Direct Synthesis of Amides from Alcohols and Amines with Liberation of $\mathrm{H}_{2}$. Science 2007, 317, 790-792.

(26) Zeng, H.; Guan, Z. Direct Synthesis of Polyamides via Catalytic Dehydrogenation of Diols and Diamines. J. Am. Chem. Soc. 2011, 133, 1159-1161.

(27) Gnanaprakasam, B.; Balaraman, E.; Gunanathan, C.; Milstein, D. Synthesis of polyamides from diols and diamines with liberation of H2. J. Polym. Sci., Part A: Polym. Chem. 2012, 50, 1755-1765.

(28) (a) Milstein, D.; Balaraman, E.; Gunanathan, C.; Gnanaprakasam, B.; Zhang, J. Novel ruthenium complexes and their uses in processes for formation and/or hydrogenation of esters, amides and derivatives thereof. U.S. Patent Appl. US20130281664A1, 2013. (b) Krall, E. M.; Klein, T. W.; Andersen, R. J.; Nett, A. J.; Glasgow, R. W.; Reader, D. S.; Dauphinais, B. C.; McIlrath, S. P.; Fischer, A. A.; Carney, M. J.; Hudson, D. J.; Robertson, N. J. Controlled hydrogenative depolymerization of polyesters and polycarbonates catalyzed by ruthenium(II) PNN pincer complexes. Chem. Commun. 2014, 50, 4884-4887. (c) Fuentes, J. A.; Smith, S. M.; Scharbert, M. T.; Carpenter, I.; Cordes, D. B.; Slawin, A. M. Z.; Clarke, M. L. On the Functional Group Tolerance of Ester Hydrogenation and Polyester Depolymerisation Catalysed by Ruthenium Complexes of Tridentate Aminophosphine Ligands. Chem. - Eur. J. 2015, 21, 10851-10860. (d) Westhues, S.; Idel, J.; Klankermayer, J. Molecular catalyst systems as key enablers for tailored polyesters and polycarbonate recycling concepts. Sci. $A d v$. 2018, 4, No. eaat9669. (e) Han, Z.; Rong, L.; Wu, J.; Zhang, L.; Wang, Z.; Ding, K. Catalytic Hydrogenation of Cyclic Carbonates: A Practical Approach from $\mathrm{CO}_{2}$ and Epoxides to Methanol and Diols. Angew. Chem., Int. Ed. 2012, 51, 13041-13045. (f) Kumar, A.; Janes, T.; Espinosa-Jalapa, N. A.; Milstein, D. Manganese Catalyzed Hydrogenation of Organic Carbonates to Methanol and Alcohols. Angew. Chem., Int. Ed. 2018, 57, 12076-12080. (g) Zubar, V.; Lebedev, Y.; Azofra, L. M.; Cavallo, L.; El-Sepelgy, O.; Rueping, M. Hydrogenation of $\mathrm{CO}_{2}$-Derived Carbonates and Polycarbonates to Methanol and Diols by Metal-Ligand Cooperative Manganese Catalysis. Angew. Chem., Int. Ed. 2018, 57, 13439-13443.

(29) (a) Kumar, A.; Janes, T.; Espinosa-Jalapa, N. A.; Milstein, D. Selective Hydrogenation of Cyclic Imides to Diols and Amines and Its Application in the Development of a Liquid Organic Hydrogen Carrier. J. Am. Chem. Soc. 2018, 140, 7453-7457. (b) Kar, S.; Rauch, M.; Kumar, A.; Leitus, G.; Ben-David, Y.; Milstein, D. Selective Room-Temperature Hydrogenation of Amides to Amines and Alcohols Catalyzed by a Ruthenium Pincer Complex and Mechanistic Insight. ACS Catal. 2020, 10, 5511-5515. (c) Hu, P.; Fogler, E.; Diskin-Posner, Y.; Iron, M. A.; Milstein, D. A novel liquid organic hydrogen carrier system based on catalytic peptide formation and hydrogenation. Nat. Commun. 2015, 6, 6859.

(30) Fogler, E.; Garg, J. A.; Hu, P.; Leitus, G.; Shimon, L. J. W.; Milstein, D. System with Potential Dual Modes of Metal-Ligand Cooperation: Highly Catalytically Active Pyridine-Based PNNH-Ru Pincer Complexes. Chem. - Eur. J. 2014, 20, 15727-15731. 
(31) Balaraman, E.; Khaskin, E.; Leitus, G.; Milstein, D. Catalytic transformation of alcohols to carboxylic acid salts and $\mathrm{H}_{2}$ using water as the oxygen atom source. Nat. Chem. 2013, 5, 122-125.

(32) https://www.gaylordchemical.com/literature/dmso-solubilitydata/ (accessed 2020-08-05).

(33) (a) Byrne, F. P.; Jin, S.; Paggiola, G.; Petchey, T. H. M.; Clark, J. H.; Farmer, T. J.; Hunt, A. J.; Robert McElroy, C.; Sherwood, J. Tools and techniques for solvent selection: green solvent selection guides. Sustainable Chem. Processes 2016, 4, 7. (b) Vignes, R. Dimethyl sulfoxide (DMSO), a new, clean, unique, superior solvent. Annual Meeting of the American Chemical Society, Arlington, VA, April 2528, 2000. (c) Xiang, J.-C.; Gao, Q.-H.; Wu, A.-X. The Applications of DMSO. Solvents as Reagents in Organic Synthesis: Reactions and Applications 2017, 315-353.

(34) Langanke, J.; Wolf, A.; Hofmann, J.; Böhm, K.; Subhani, M. A.; Müller, T. E.; Leitner, W.; Gürtler, C. Carbon dioxide $\left(\mathrm{CO}_{2}\right)$ as sustainable feedstock for polyurethane production. Green Chem. 2014, $16,1865-1870$

(35) Keijer, T.; Bakker, V.; Slootweg, J. C. Circular chemistry to enable a circular economy. Nat. Chem. 2019, 11, 190-195.

(36) Molchanov, S.; Gryff-Keller, A. Solvation of Amides in DMSO and $\mathrm{CDCl}_{3}$ : An Attempt at Quantitative DFT-Based Interpretation of ${ }^{1} \mathrm{H}$ and ${ }^{13} \mathrm{C}$ NMR Chemical Shifts. J. Phys. Chem. A 2017, 121, 96459653.

(37) Chand, A.; Chowdhuri, S. Effects of dimethyl sulfoxide on the hydrogen bonding structure and dynamics of aqueous N-methylacetamide solution. J. Chem. Sci. 2016, 128, 991-1001.

(38) Kumar, A.; Espinosa-Jalapa, N. A.; Leitus, G.; Diskin-Posner, Y.; Avram, L.; Milstein, D. Direct Synthesis of Amides by Dehydrogenative Coupling of Amines with either Alcohols or Esters: Manganese Pincer Complex as Catalyst. Angew. Chem., Int. Ed. 2017, 56, 14992-14996.

(39) Espinosa-Jalapa, N. A.; Kumar, A.; Leitus, G.; Diskin-Posner, Y.; Milstein, D. Synthesis of Cyclic Imides by Acceptorless Dehydrogenative Coupling of Diols and Amines Catalyzed by a Manganese Pincer Complex. J. Am. Chem. Soc. 2017, 139, 1172211725 .

(40) Kumar, A.; Janes, T.; Espinosa-Jalapa, N. A.; Milstein, D. Manganese Catalyzed Hydrogenation of Organic Carbonates to Methanol and Alcohols. Angew. Chem., Int. Ed. 2018, 57, 1207612080 .

(41) Mathis, C. L.; Geary, J.; Ardon, Y.; Reese, M. S.; Philliber, M. A.; VanderLinden, R. T.; Saouma, C. T. Thermodynamic Analysis of Metal-Ligand Cooperativity of PNP Ru Complexes: Implications for $\mathrm{CO}_{2}$ Hydrogenation to Methanol and Catalyst Inhibition. J. Am. Chem. Soc. 2019, 141, 14317-14328.

(42) Bruffaerts, J.; von Wolff, N.; Diskin-Posner, Y.; Ben-David, Y.; Milstein, D. Formamides as Isocyanate Surrogates: A Mechanistically Driven Approach to the Development of Atom-Efficient, Selective Catalytic Syntheses of Ureas, Carbamates, and Heterocycles. J. Am. Chem. Soc. 2019, 141, 16486-16493.

(43) Dub, P. A.; Gordon, J. C. Metal-Ligand Bifunctional Catalysis: The "Accepted" Mechanism, the Issue of Concertedness, and the Function of the Ligand in Catalytic Cycles Involving Hydrogen Atoms. ACS Catal. 2017, 7, 6635-6655.

(44) Sinha, V.; Govindarajan, N.; de Bruin, B.; Meijer, E. J. How Solvent Affects C-H Activation and Hydrogen Production Pathways in Homogeneous Ru-Catalysed Methanol Dehydrogenation Reactions. ACS Catal. 2018, 8, 6908-6913.

(45) Smith, N. E.; Bernskoetter, W. H.; Hazari, N. The Role of Proton Shuttles in the Reversible Activation of Hydrogen via MetalLigand Cooperation. J. Am. Chem. Soc. 2019, 141, 17350-17360.

(46) Rezayee, N. M.; Samblanet, D. C.; Sanford, M. S. IronCatalyzed Hydrogenation of Amides to Alcohols and Amines. ACS Catal. 2016, 6, 6377-6383.

(47) Kar, S.; Sen, R.; Kothandaraman, J.; Goeppert, A.; Chowdhury, R.; Munoz, S. B.; Haiges, R.; Prakash, G. K. S. Mechanistic Insights into RutheniumPincer-Catalyzed Amine-Assisted Homogeneous
Hydrogenation of $\mathrm{CO}_{2}$ to Methanol. J. Am. Chem. Soc. 2019, 141, $3160-3170$.

(48) Artus Suarez, L.; Jayarathne, U.; Balcells, D.; Bernskoetter, W. H.; Hazari, N.; Jaraiz, M.; Nova, A. Rational selection of co-catalysts for the deaminative hydrogenation of amides. Chem. Sci. 2020, 11, 2225-2230.

(49) Artus Suárez, L.; Culakova, Z.; Balcells, D.; Bernskoetter, W. H.; Eisenstein, O.; Goldberg, K. I.; Hazari, N.; Tilset, M.; Nova, A. The Key Role of the Hemiaminal Intermediate in the Iron-Catalyzed Deaminative Hydrogenation of Amides. ACS Catal. 2018, 8, 87518762.

(50) Leischner, T.; Artus Suarez, L.; Spannenberg, A.; Junge, K.; Nova, A.; Beller, M. Highly selective hydrogenation of amides catalysed by a molybdenum pincer complex: scope and mechanism. Chem. Sci. 2019, 10, 10566-10576.

(51) Gusev, D. G. Revised Mechanisms of the Catalytic Alcohol Dehydrogenation and Ester Reduction with the Milstein PNN Complex of Ruthenium. Organometallics 2020, 39, 258-270.

(52) John, J. M.; Loorthuraja, R.; Antoniuk, E.; Bergens, S. H. Catalytic hydrogenation of functionalized amides under basic and neutral conditions. Catal. Sci. Technol. 2015, 5, 1181-1186.

(53) Rastetter, W. H.; Wagner, W. R.; Findeis, M. A. Mechanism of oxaziridine fragmentation by amines. J. Org. Chem. 1982, 47, 419422. 